\title{
Bivariate linkage scan for reading disability and attention-deficit/hyperactivity disorder localizes pleiotropic loci
}

\author{
J. Gayán, ${ }^{1}$ E.G. Willcutt, ${ }^{2}$ S.E. Fisher, ${ }^{1}$ C. Francks, ${ }^{1}$ L.R. Cardon, ${ }^{1}$ R.K. Olson, ${ }^{2}$ \\ B.F. Pennington, ${ }^{3}$ S.D. Smith, ${ }^{4}$ A.P. Monaco, ${ }^{1}$ and J.C. DeFries ${ }^{2}$ \\ ${ }^{1}$ Wellcome Trust Centre for Human Genetics, University of Oxford, UK; ${ }^{2}$ Institute for Behavioral Genetics, University \\ of Colorado, Boulder, USA; ${ }^{3}$ Department of Psychology, University of Denver, USA; ${ }^{4}$ Munroe Meyer Institute, \\ University of Nebraska Medical Center, Omaha, USA
}

\begin{abstract}
Background: There is a growing interest in the study of the genetic origins of comorbidity, a direct consequence of the recent findings of genetic loci that are seemingly linked to more than one disorder. There are several potential causes for these shared regions of linkage, but one possibility is that these loci may harbor genes with manifold effects. The established genetic correlation between reading disability (RD) and attention-deficit/hyperactivity disorder (ADHD) suggests that their comorbidity is due at least in part to genes that have an impact on several phenotypes, a phenomenon known as pleiotropy. Methods: We employ a bivariate linkage test for selected samples that could help identify these pleiotropic loci. This linkage method was employed to carry out the first bivariate genome-wide analysis for RD and ADHD, in a selected sample of 182 sibling pairs. Results: We found evidence for a novel locus at chromosome 14q32 (multipoint LOD $=2.5$; singlepoint LOD $=3.9$ ) with a pleiotropic effect on $\mathrm{RD}$ and ADHD. Another locus at 13q32, which had been implicated in previous univariate scans of RD and ADHD, seems to have a pleiotropic effect on both disorders. 20q11 is also suggested as a pleiotropic locus. Other loci previously implicated in RD or ADHD did not exhibit bivariate linkage. Conclusions: Some loci are suggested as having pleiotropic effects on RD and ADHD, while others might have unique effects. These results highlight the utility of this bivariate linkage method to study pleiotropy. Keywords: Dyslexia, attention-deficit/hyperactivity, genome-wide, genetic linkage, pleiotropy. Abbreviations: RD: reading disability; ADHD: attention-deficit/hyperactivity disorder; LOD: log of the odds ratio; DYX: dyslexia; QTL: quantitative trait locus; CLDRC: Colorado Learning Disabilities Research Center; WR: word recognition; PA: phonological awareness; PD: phonological decoding; OC: orthographic coding; ADHD: attention-deficit/hyperactivity disorder or total ADHD symptoms; HYP: hyperactivity; INAT: inattention; IBD: identity by descent.
\end{abstract}

Recent genome scans have established the existence of chromosomal regions linked with more than one psychiatric disorder, suggesting that the comorbidity observed among these disorders may have a genetic origin. Although there are multiple potential explanations for these findings, a compelling hypothesis is that some of these regions harbor genes that have effects on multiple phenotypes (pleiotropic genes). Therefore, the study of the genetic nature of comorbid disorders has recently gained considerable attention. Here we employ a method to analyze comorbidity by means of a bivariate linkage regression test of selected sibling data. Genetic linkage analysis is traditionally used to determine whether a disorder is influenced by a gene that is located in a specific region of a chromosome. We present results of a bivariate genome-wide analysis of reading disability (RD) and attention-deficit/hyperactivity disorder (ADHD), suggesting potential pleiotropic loci.

$\mathrm{RD}$, also commonly referred to as dyslexia, is a specific language disorder characterized by unexpected difficulties in single word decoding, usually reflecting insufficient phonological processing (Lyon, 1995). ADHD is a neurobehavioral disorder manifested by symptoms of inattention, hyperactivity and/or impulsivity. RD and ADHD are two of the most common childhood disorders, each affecting about 5-10\% of the population (American Psychiatric Association, 1994). Measures of RD and ADHD exhibit moderate correlations, and the two disorders co-occur in about $15-40 \%$ of cases (Willcutt \& Pennington, 2000).

The potential causes of the comorbidity between $\mathrm{RD}$ and ADHD are multiple, but a common genetic etiology is possibly the most convincing explanation (Willcutt, Pennington, Olson, Chhabildas, \& Hulslander, 2005). Family and twin studies have demonstrated that both RD and ADHD are heritable $\left(h^{2}=.57-.93\right)$ (Gayán \& Olson, 2001; Willcutt, Pennington, Olson, \& DeFries, submitted). Heritability in this context provides a measure of the extent to which a disorder is due to genetic influences. Thus, RD and ADHD are both influenced substantially by genetic factors. More importantly, twin analyses suggest that they are influenced to some degree by the same genes, as indicated by moderate bivariate heritability. This effect can be measured by means of a genetic correlation $\left(r_{g}\right)$, which ranges for 
these two disorders from .37 to .70 , indicating that pleiotropic genes are at play. The genetic correlation between RD and hyperactivity/impulsivity symptoms is lower $\left(r_{g}=.37-.40\right)$ than that between RD and inattention symptoms $\left(r_{g}=.39-.70\right)$ and $\mathrm{RD}$ and Total ADHD symptoms $\left(r_{g}=.43-63\right)$ (Willcutt et al., submitted). Thus, RD and ADHD should exhibit simultaneous linkage to some genetic loci, but perhaps more strongly for RD and symptoms of inattention.

The actual genes involved in RD and ADHD are still unknown, although much progress has occurred recently thanks to the advances in genetic methodology. Genetic markers, that is, DNA variants with a known chromosomal location (or locus), are essential to linkage analysis. Until recently, linkage analyses targeted specific chromosomal regions where known genetic markers were located, suggesting that a disorder was linked to that locus, that is, inherited through a gene located in the region of the genetic marker. The improvements in this field have resulted in an abundance of genetic markers, such that it is now possible to analyze the entire genome for linkage to a disorder, what is commonly known as a genome scan. A locus or linkage region is commonly named by its chromosomal location which is symbolized by a combination of numbers and letters: First the chromosome symbol (1-22 for the 22 autosomal chromosomes or X-Y for the sex chromosome), next the chromosome arm ( $p$ for the short or q for the long arm), and then a number that denotes the chromosomal band. Regions defined in this manner can be of very different sizes and may contain a variable number of genes. The size of chromosomal regions is usually measured in centimorgan (cM) units. In human beings, one centimorgan is equivalent, on average, to one million DNA base pairs.

Briefly, linkage analysis takes advantage of the fact that two genes that are close together on a chromosome tend to be transmitted together across many generations of a family, whereas genes that are far apart are transmitted independently from parent to child. Therefore, if a specific genetic marker whose location in the genome is known tends to co-occur with a disorder within a family, this suggests that a gene influencing the disorder is close to the marker. Linkage analysis typically does not identify the specific gene that leads to increased risk for a disorder. Instead, this approach identifies regions of the genome that are likely to contain a gene influencing a disorder, and these regions can then be targeted for more extensive analysis, usually by means of association analysis.

Genetic association analysis tests the association of a genetic marker and a disorder. Some forms of this test are akin to the traditional case-control experimental design, where cases (those with a particular gene) and controls (those without the gene) are compared on basis to a disorder. Because genetic association has better spatial resolution than linkage, it is commonly used to explore small linkage regions where the risk gene may be located, or it may directly analyze the candidate gene itself. A gene may be considered a candidate to influence a disorder if it is located in a region that has shown linkage evidence for that disorder, or if it is involved in the specific physiological processes that are associated with the disorder.

Targeted linkage and association analyses and genome scans, carried out independently for RD and ADHD, have identified a number of potential susceptibility loci, that is, loci that may influence risk of being affected with a disorder (see Table 1), including the $8 \mathrm{RD}$ susceptibility loci in the Human Gene Nomenclature Database (DYX1-DYX8): DYX1 (Smith, Kimberling, Pennington, \& Lubs, 1983; Bisgaard, Eiberg, Møller, Niebuhr, \& Morh, 1987; Smith, Kimberling, \& Pennington, 1991; Fulker et al., 1991; Rabin et al., 1993; Grigorenko et al., 1997; Schulte-Körne et al., 1998; Nopola-Hemmi et al., 2000; Morris et al., 2000; Taipale et al., 2003; Marino et al., 2004; Scerri et al., 2004; Wigg et al., 2004; Cope et al., 2004), DYX2 (Smith et al., 1991; Cardon et al., 1994, 1995; Gayán et al., 1995; Grigorenko et al., 1997; Schulte-Körne et al., 1998; Field \& Kaplan 1998; Gayán et al., 1999; Fisher et al., 1999; Petryshen, Kaplan, Liu, \& Field, 2000; Grigorenko, Wood, Meyer, \& Pauls, 2000; Kaplan et al., 2002; Fisher et al., 2002a; Willcutt et al., 2002; Grigorenko et al., 2003; Marlow et al., 2003; Defienbacher et al., 2004; Francks et al., 2004), DYX3 (Fagerheim et al., 1999; Fisher et al., 2002a; Petryshen, Kaplan, Hughes, Tzenova, \& Field, 2002; Kaminen et al., 2003; Loo et al., 2004), DYX4 (Field \& Kaplan, 1998; Petryshen et al., 2001), DYX5 (Nopola-Hemmi et al., 2001; Fisher et al., 2002a), DYX6 (Fisher et al., 2002a; Marlow et al., 2003), DYX7 (Hsiung, Kaplan, Petryshen, Lu, \& Field, 2004), and DYX8 (Rabin et al., 1993; Froster, Schulte-Körne, Hebebrand, \& Remschmidt, 1993; Grigorenko et al., 2001; Tzenova, Kaplan, Petryshen, \& Field, 2004). For ADHD, there have been four genome scans carried out from three independent groups (Fisher et al., 2002b; Bakker et al., 2003; Ogdie et al., 2003; Arcos-Burgos et al., 2004). There is now evidence for a specifically identified gene believed to influence RD (Taipale et al., 2003), although it is likely to only be relevant for subgroups of the affected population (Scerri et al., 2004; Wigg et al., 2004; Cope et al., 2004). In addition, based on evidence that suggests that dysfunction in the dopamine neurotransmitter system is associated with ADHD, several studies have examined genes in the dopamine pathway (Faraone et al., in press). Results of these studies indicate that a subset of these genes do indeed increase risk for ADHD. However, the effect size of each of these genes is small, and their combined effects explain a relatively modest proportion of the total genetic variance in ADHD symptoms (Faraone, 
Table 1 Overview of RD and ADHD loci (approximately LOD scores $\geq 1$ ) identified in previous linkage studies. The chromosomal region of linkage and most relevant citations for each result are provided. Citations for the 8 RD susceptibility loci in the Human Gene Nomenclature Database are cited in the Introduction section

\begin{tabular}{lll}
\hline Chromosome & \multicolumn{1}{c}{ RD } & \multicolumn{1}{c}{ ADHD } \\
\hline 1p34-36 & DYX8 & \\
2p25 & Fisher et al. (2002a) & \\
2p11-16 & DYX3 & \\
3p12-q13 & DYX5 & Bakker et al. (2003) \\
3q29 & Fisher et al. (2002a) & Bakker et al. (2003) \\
4p16 & & Arcos-Burgos et al. (2004) \\
4q12-13 & Fisher et al. (2002a) & Bakker et al. (2003) and Ogdie et al. (2003) \\
5p12-13 & & Arcos-Burgos et al. (2004) \\
5q33 & & Ogdie et al. (2003) \\
6p22-q16 & DYX2 and DYX4 & Bakker et al. (2003) \\
6q26 & & Bakker et al. (2003) \\
7p13 & & \\
$7 q 32$ & Kaminen et al. (2003) & \\
8p23 & Fisher et al. (2002a) & Arcos-Burgos et al. (2004) \\
8q11 & & \\
9p22 & Fisher et al. (2002a) & Bakker et al. (2003) \\
9q33 & & Bakker et al. (2003) \\
10cen-q11 & Loo et al. (2004) & \\
11p15 & DYX7 & Ogdie et al. (2003) and Arcos-Burgos et al. (2004) \\
11q22-25 & & Bakker et al. (2003) \\
13q12-33 & Fisher et al. (2002a) & Bakker et al. (2003) \\
14q31 & & Bakker et al. (2003) \\
15q15-21 & DYX1 & Ogdie et al. (2003) \\
16p13 & Loo et al. (2004) & Ogdie et al. (2003) and Arcos-Burgos et al. (2004) \\
17p11-q22 & Loo et al. (2004) & \\
$18 p 11$ & DYX6 & Ogdie et al. (2003) \\
18q21-22 & Fisher et al. (2002a) & \\
20q13 & & \\
$21 q 21-22$ & Fisher et al. (2002a) & \\
\hline
\end{tabular}

Doyle, Mick, \& Biederman, 2001; Maher, Marazita, Ferrell, \& Vanyukov, 2002). Some of the identified loci have been replicated in several samples, while other loci are linked only sporadically. This is an observed phenomenon for many psychiatric disorders and it is probably due to the combination of many factors such as false positive findings, the genetic heterogeneity of the disorder, sampling issues (lack of power, random fluctuations), or different experimental designs (ascertainment, phenotype, analysis) across studies (Fisher \& DeFries, 2002).

There is some overlap between linkage regions suggested by genome-wide linkage analyses of RD and ADHD, which might be explained by pleiotropy for these disorders. These regions include $3 q 13$, 4q12-13, 6p22-q16, 10cen-q11, 13q12-33, 15q15$21,16 \mathrm{p} 13$ and 17p11-q22 (see Table 1). Although these regions of shared linkage are still only very tentative, we have listed them because of their potential informativeness. More recently, genomewide linkage analyses of measures of reading ability were performed in a sample of affected sibling pairs with ADHD. Their results revealed areas of overlapping and non-overlapping linkage to RD and ADHD, and suggested that loci on 10q, 16p, and 17q may influence both RD and ADHD (Loo et al., 2004).

Although these results may indicate that a gene or genes in these regions increase risk for two or more of these disorders, several alternative explanations could account for the overlapping linkage results across studies of different disorders. Because many of these regions are defined by weak linkage results (the customary linkage test-statistic is a log-of-theodds (LOD) score, and the LOD $\geq 1$ criteria used in Table 1 is considered as only tentative linkage), at least a subset of these initial results are likely to be false positives, and need replication in independent samples. In addition, the chromosomal regions implicated by these results are often quite wide due to low statistical power, marker informativeness, and sampling error, suggesting that some results that appear to overlap may instead reflect the influence of two distinct genes that are relatively far apart on the same chromosome. Finally, even if the identified chromosomal region has a true effect on two or more disorders, this genetic effect could be due to linked genes that influence each disorder independently, a gene with pleiotropic effects, or both.

Bivariate linkage analysis can begin to clarify these results by testing simultaneously if loci are linked to both traits in the same families. The bivariate approach capitalizes on the shared genetic variance between the two traits, and thus is the preferred method to assess the shared genetic linkage between two disorders that may explain their comorbidity. To date, only one study has tested for bivariate linkage of RD and ADHD, and this study was confined to a region of chromosome $6 \mathrm{p} 21$, which 
the researchers targeted because a locus for RD in this region has been replicated in several studies (Willcutt et al., 2002). These analyses revealed suggestive evidence for linkage for several of the reading and ADHD phenotypes, implying that this region may contain a locus with pleiotropic effects on RD and ADHD.

In summary, previous studies suggest that $\mathrm{RD}$ and ADHD are due to common genetic influences, and initial univariate and bivariate linkage analyses have revealed promising results. In this paper we present results from the first bivariate genome-wide analysis of RD and ADHD. Given the current interest in genetic origins of comorbidity, as well as the increasing number of genome scan datasets, we anticipate that this approach may become a useful tool to understand the etiology of comorbidity between complex disorders.

\section{Methods}

\section{Subjects}

The Colorado Learning Disabilities Research Center (CLDRC) (DeFries et al., 1997) has ascertained and tested a large number of identical and fraternal twins and their non-twin siblings between 8 and 19 years of age. The initial ascertainment was based on a school history for reading disability in at least one twin of each pair. A control sample of twins with no school history of reading disability was used to standardize the measures. The twins and their non-twin siblings were then evaluated in the laboratory with an extensive battery of standard psychometric and experimental tests. For this study, fraternal twins and their biological siblings were selected. In the case of identical twins, only one member of each pair, chosen at random, and all their biological siblings were also chosen. Twin zygosity was determined by questionnaire (Nichols \& Bilbro, 1966), and blood analysis was performed in cases of ambiguity. Because RD and ADHD are comorbid, a subgroup of these subjects also exhibited ADHD symptoms, which were assessed from parental ratings. This study was approved by the Human Research Committee of the University of Colorado at Boulder.

The sample consisted of 505 individuals forming 119 nuclear families. Ninety-five families had 2 siblings, 19 had 3 siblings, and 5 had 4 siblings, with an average sibship size of 2.24, and a total of 182 sibling pairs. There were 156 male siblings and 111 female siblings, with a mean age of 11.58 years old (range 8-19). Of the 182 sib pairs, 67 were male, 33 were female, and 82 were opposite-sex pairs.

\section{Phenotypes}

A few representative reading and language tests were chosen from the rich battery of tests available at the CLDRC. Reading and language skills were assessed with tests of word recognition (WR), phonological awareness (PA), phonological decoding (PD), and orthographic coding $(\mathrm{OC})$, completed individually by each participant. Word recognition requires subjects to read aloud words, and was measured with the Peabody individual achievement test (Dunn \& Markwardt, 1970) and our experimental timed word recognition test (Olson, Wise, Conners, Rack, \& Fulker, 1989). Phoneme awareness is the ability to isolate and manipulate abstract sub-syllabic phonemes in speech, and it was measured with phoneme transposition and phoneme deletion tasks (Olson, Forsberg, \& Wise, 1994). Phonological decoding was measured through the oral reading of pronounceable nonwords (Olson et al., 1989). Orthographic coding is the ability to recognize words' specific orthographic patterns, and was tested here through an orthographic forced-choice task (Olson et al., 1989). All these measures have been described extensively elsewhere (Gayán et al., 1999).

The DSM-III (American Psychiatric Association, 1980) version of the Diagnostic Interview for Children and Adolescents, Parent Report Version (DICA) (Herjanic \& Reich, 1982), was used to assess symptoms of ADHD. In addition to the total ADHD symptom count (ADHD), a previous factor analysis revealed that the DICA ADHD symptoms load on separate factors characterized by symptoms of hyperactivity-impulsivity (HYP) and inattention (INAT) (Willcutt \& Pennington, 2000). In a small subset of our sample $(N=25)$ who completed both the DICA and a measure of DSM-IV ADHD, the inattention and hyperactivity-impulsivity factor scores based on the DICA were highly correlated with their corresponding DSM-IV symptom dimension $(r=.81-.85)$.

Age-adjusted phenotypes were expressed in standard deviation (SD) units relative to the normal population. The population parameters were estimated from the large CLDRC dataset. In addition, the ADHD phenotypes were multiplied by -1 so that lower scores indicate greater severity on all measures (i.e., deficits on the reading measures and elevations of ADHD symptoms).

\section{Genotyping}

Siblings and parents contributed blood from which DNA was extracted. These subjects were genotyped using highly variable (polymorphic) genetic markers covering the entire genome (that is, all 23 pairs of chromosomes) in a previous study (Fisher et al., 2002a). Genetic markers were selected to be polymorphic, that is, have different forms (alleles), so that they are informative about inheritance. Humans have two copies (that is, a pair) of each chromosome, and therefore two copies of each gene or genetic marker, one inherited from the father and the other from the mother. Provided that a child and both parents have been genotyped, highly polymorphic markers have enough alleles that it is usually possible to determine the parental origin of a child's alleles. If two siblings are genotyped, it is possible to determine the identity-by-descent (IBD), that is, the number of alleles $(0,1$, or 2$)$ that the two siblings have inherited from the same parent. IBD therefore provides a measure of the genetic relatedness of two subjects at that specific chromosomal location.

For the current study, we analyzed data from 391 genetic markers across all 22 autosomal chromosomes. The $\mathrm{X}$ chromosome was excluded because of linkage software limitations. Most of these markers came from the ABI PRISM LMS2-MD10 panels (Applied Biosystems). 


\section{Linkage analysis}

Identity-by-descent (IBD) can be estimated at each genetic marker using only information from that marker (singlepoint), or also at intervals between markers using information from multiple markers (multipoint). IBD estimation depends on allele frequencies, which can be obtained from the sample in the study or from a more general population if available. For multipoint analysis, a genetic marker map provides the order and distance (usually in centimorgan units) of all markers along each chromosome. Although there are gender differences, it is customary to average these marker maps across genders.

Multipoint identity-by-descent (IBD) allele-sharing was estimated at 2-centimorgan intervals throughout the 22 autosomal chromosomes with the pedigree analysis package MERLIN (Abecasis, Cherny, Cookson, $\&$ Cardon, 2002), using sample allele frequencies and sex-averaged marker maps (Fisher et al., 2002a). Singlepoint analyses were carried out only for markers at those locations where multipoint linkage results suggested further exploration (LOD score $\geq 1$ ).

Because the sample was selected for RD, we employed the DeFries-Fulker multiple regression linkage test implemented in QMS2 (Lessem \& Cherny, 2001). This regression model was originally designed for twin analysis and is especially suitable for selected continuous data (DeFries \& Fulker, 1985). It is indeed a powerful test for genetic influences in groups selected for an extreme deficit. This model was adapted to sib pair linkage analysis and used successfully in several studies (Fulker et al., 1991; Cardon et al., 1994; Gayán et al., 1999; Kaplan et al., 2002; Fisher et al., 2002a). Briefly, a sib pair is composed of a proband (ascertained or affected individual) and a co-sib. The linkage test involves the regression of the co-sib score on the proband score and the estimated proportion of alleles shared IBD (which are imported from MERLIN). Because the probands have been selected to have low scores in reading, they form the low tail of a normal distribution of reading scores. Therefore, the co-sib scores are expected to regress back to the population mean. If a genetic locus has an effect on a disorder, then co-sibs who share 2 alleles with the proband at this locus are expected to regress less than co-sibs who share only 1 allele, and these are expected to regress less than co-sibs who share no alleles at the locus with the proband. In simple terms, this linkage method is merely testing whether the phenotypic resemblance between siblings (measured by the co-sib regression towards the population mean) is related to their genetic resemblance (as measured by IBD). In other words, the method examines whether siblings are more similar for a trait the higher their levels of genetic resemblance at a certain locus.

Because of its flexibility, this regression method can easily adapt the use of covariates (LaBuda, DeFries, \& Fulker, 1986), and has been extended for bivariate twin (Olson, Rack, Conners, DeFries, \& Fulker, 1991; Gayán $\&$ Olson, 2001) and linkage (Willcutt et al., 2002) analysis. For bivariate linkage analysis, a co-sib score on one phenotype (i.e., ADHD) is regressed on the proband score on another phenotype (i.e., RD) and the estimated IBD allele-sharing. In the present study, the bivariate linkage test was carried out with a version of QMS2 especially modified for this purpose. The obtained $t$-statistic for the test of linkage was transformed into a LOD score using the formula $L O D=\frac{t^{2}}{(2 \ln 10)}$.

Finally, simulations were used to evaluate the true significance of the empirical linkage results. The phenotypic (test scores) and genotypic (genetic markers) data analyzed in the study can be randomly shuffled to determine the distribution of the test-statistic under the observed data, which can then be employed to derive empirical significance values. MERLIN implements these simulations by replacing the observed genetic marker data with simulated genetic markers conditional on the actual family structure, marker maps and allele frequencies used, as well as missing data patterns. In this manner, 15,000 genome scan replicates were simulated in MERLIN and analyzed for linkage in QMS2 with the phenotypes employed in this study. We also carried out 100,000 simulations on our most significant linkage result to have a better estimate of this small probability. These results were used to assess the significance of each linkage statistic reported in this study. These empirical significance levels were uncorrected for multiple testing.

\section{Results}

Phenotypic data were available for 214-265 probands and siblings (depending on the phenotype), with means .59-1.57 SD below the population average (Variances $=1.46-2.25$ ). All phenotypic correlations were positive and most were significant (see Table 2). In general, we found large correlations among word recognition (WR), phonological awareness (PA), and phonological decoding (PD), slightly lower among these and orthographic coding (OC), medium-large among ADHD measures, moderate between reading disability $(\mathrm{RD})$ measures and ADHD and inattention (INAT), and low between RD and hyperactivity (HYP).

Because the sample was originally ascertained for reading deficits, we estimated the rate of comorbid ADHD within this RD sample. RD or ADHD affected individuals were defined as having scores of 1.5 or more SD below the population mean in the RD or ADHD phenotype, respectively. On this basis, 36\% of $\mathrm{RD}$ subjects also met this criterion for ADHD.

Table 2 Phenotypic correlations among the reading and language tasks and ADHD measures

\begin{tabular}{lllllll}
\hline & WR & PA & PD & OC & ADHD & HYP \\
\hline PA & $.73^{*}$ & & & & & \\
PD & $.84^{*}$ & $.71^{*}$ & & & & \\
OC & $.63^{*}$ & $.48^{*}$ & $.60^{*}$ & & & \\
ADHD & $.28^{*}$ & $.23^{*}$ & $.15^{*}$ & $.22^{*}$ & & \\
HYP & $.14^{*}$ & .14 & .04 & .12 & $.82^{*}$ & \\
INAT & $.32^{*}$ & $.26^{*}$ & $.20^{*}$ & $.25^{*}$ & $.88^{*}$ & $.46^{*}$ \\
\hline
\end{tabular}

*Denotes significant $(p$-value $<.05)$ correlation. $\mathrm{WR}=$ word recognition, $\mathrm{PA}=$ phonological awareness, $\mathrm{PD}=$ phonological decoding, $\mathrm{OC}=$ orthographic coding, $\mathrm{ADHD}=$ total ADHD symptoms, HYP = hyperactivity, INAT = inattention. 
Univariate linkage results for the RD phenotypes in the present sample have been published previously (Fisher et al., 2002a), so we do not present these results here. Univariate linkage analyses were performed for ADHD, selecting as probands individuals 1.5 or more $\mathrm{SD}$ below the population mean in the ADHD total symptom count. For the bivariate linkage analysis we used the RD phenotypes as proband variables, treating the ADHD phenotype as co-sib variables. To ensure probands were poor readers, they were selected to be $-1.5 \mathrm{SD}$ on the relevant RD phenotype. The number of selected sib-pairs for each phenotype was: $A D H D=54$, $\mathrm{WR}-\mathrm{ADHD}=85, \mathrm{PA}-\mathrm{ADHD}=48, \mathrm{PD}-\mathrm{ADHD}=73$, OC-ADHD $=54$.

Figure 1 plots the multipoint linkage results across the 22 autosomal chromosomes. For the sake of clarity, only the most informative phenotypes (univariate ADHD total symptom count, and the bivariate phenotypes PA-ADHD and OC-ADHD) are plotted. Main linkage peaks are found on chromosomes 14 (OC-ADHD and ADHD) and 20
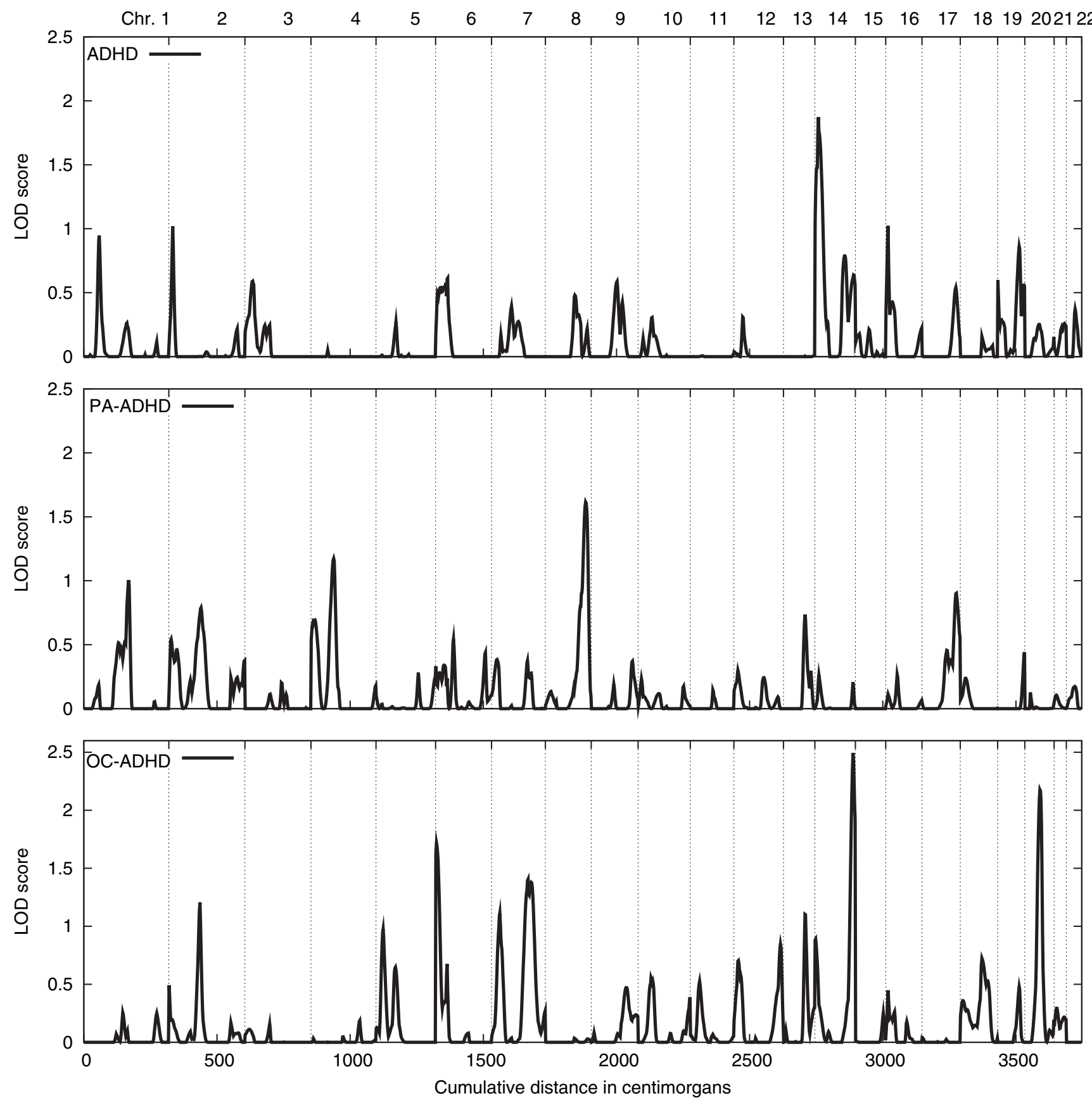

Figure 1 Multipoint linkage results (as LOD scores on the vertical axis) for the univariate ADHD phenotype and the bivariate PA-ADHD, and OC-ADHD phenotypes across the 22 autosomal chromosomes. The horizontal axis displays the chromosome number on the top of the figure and the cumulative distance in centimorgans on the bottom. Distinct linkage peaks (LOD score $\geq 1.5$ ) are visible on chromosome 14 for the univariate ADHD phenotype, chromosome 8 for PA-ADHD, and chromosomes 6, 14 and 20 for OC-ADHD 
(OC-ADHD), with smaller peaks on several other chromosomes, such as 6 (OC-ADHD) and 8 (PAADHD). The height of the peak indicates the strength of the linkage between the marker and the phenotype. Although these main peaks were not consistent across phenotypes, they were often supported by smaller peaks for other phenotypes.

A summary of the main multipoint linkage results, for the univariate and bivariate tests involving total ADHD symptoms (ADHD, WR-ADHD, PA-ADHD, PDADHD and OC-ADHD) is presented in Table 3. Although they only provide suggestive evidence of linkage in this study, and therefore should be interpreted with caution, we have chosen to present all multipoint linkage results with LOD scores $\geq 1$ for possible use in the interpretation of future studies. Other linked phenotypes at the same region are also listed. In sum, there were 15 chromosomal regions identified by these analysis.

There is suggestive evidence (LOD $\geq 2.2$ ) for bivariate linkage to chromosomes 14q32 (OC-ADHD $\mathrm{LOD}=2.5)$ and 20q11 (OC-ADHD LOD $=2.2$ ), indicating potential pleiotropic loci. The $14 \mathrm{q} 32$ locus is linked to several phenotypes, implying a common effect, shared between ADHD and the different reading components. There is also an interesting univariate linkage peak for ADHD in $14 \mathrm{q} 12(\mathrm{LOD}=1.9)$, but this locus is probably too far from 14q32 to be considered the same region of linkage.

Singlepoint linkage was analyzed at those chromosomal segments where the most significant multipoint results were found, with results consistent with the multipoint analyses. We found significant evidence for linkage to $14 \mathrm{q} 32$ with a singlepoint LOD $=3.9$ (empirical $p$-value $=.00007$ ) for marker D14S985. Two other notable singlepoint peaks were located at $16 \mathrm{p} 13$ (ADHD $\mathrm{LOD}=2.4$, empirical $p$-value $=.001)$ and 20q11 (OC-ADHD LOD $=2.3$, empirical $p$-value $=.001$ ).

The phenotypic correlation of ADHD total symptoms and its dimensions (inattention and hyperactivity/impulsivity) is very high $(r=.82-.88)$. Nonetheless, we also performed genome scans on the ADHD dimensions in case some loci might exhibit specific effects to these phenotypes. The strongest bivariate linkage results for the ADHD dimensions were found to chromosomes 8q24 (PA-INAT LOD = 2.3), 13q32 (OC-HYP LOD $=2.4$ ), and $17 \mathrm{q} 25$ (PAINAT LOD $=2.2$ ). There are also strong univariate linkage peaks for the ADHD measures in 7q21 (HYP LOD $=3.2$ ) and 9p24 (INAT LOD = 2.6).

Results vary widely in the number of phenotypes linked to each locus. 13q32 is consistently linked to several phenotypes, both in multipoint and singlepoint tests, supporting the validity of this locus. The opposite scenario is reflected in $7 \mathrm{q} 21$, where only one univariate phenotype (HYP) shows linkage, but the signal is strong enough ( $\mathrm{LOD}=3.2$ at marker D7S527) to consider it a valid putative locus.

\section{Discussion}

Recent genome-wide linkage scans have identified putative loci that may have manifold effects. For example, a targeted study has claimed pleiotropic effects of a chromosome 3 locus on speech-sound disorder and reading (Stein et al., 2004). To better understand this potential genetic comorbidity, we advocate the use of a bivariate linkage approach (Willcutt et al., 2002). In this paper we have employed this simple bivariate regression-based linkage model and have carried out the first bivariate linkage genome-wide analysis, using a sib-pair sample selected for reading disability, with comorbid ADHD.

Table 3 Multipoint linkage peaks (LOD score $\geq 1$ ) are reported at positions in centimorgans (cM) from the first marker in each chromosome. Maximum LOD scores (with corresponding empirical pointwise $p$-value) are reported for the most significant phenotype. Other linked phenotypes are listed, with LOD score and peak location in centimorgans

\begin{tabular}{|c|c|c|c|}
\hline Chromosome & $\mathrm{cM}$ & LOD ( $p$-value) & Phenotype(s) \\
\hline $1 \mathrm{p} 13-\mathrm{q} 21$ & 168 & $1.0(.02)$ & PA-ADHD, WR-ADHD (1.0@ @ 150) \\
\hline $2 \mathrm{p} 25$ & 14 & $1.0(.02)$ & ADHD \\
\hline 2p11-q14 & 118 & $1.4(.009)$ & WR-ADHD, OC-ADHD (1.2@ 116), PA-ADHD(0.8@ 120) \\
\hline $4 \mathrm{q} 13$ & 84 & $1.2(.01)$ & PA-ADHD \\
\hline $5 q 31$ & 158 & $1.3(.01)$ & PD-ADHD \\
\hline $6 \mathrm{p} 24-25$ & 2 & $1.7(.004)$ & OC-ADHD \\
\hline $7 \mathrm{p} 15-21$ & 30 & $1.1(.02)$ & OC-ADHD \\
\hline $7 q 22$ & 136 & $1.4(.009)$ & OC-ADHD, PD-ADHD (0.8@ @ 132) \\
\hline $8 \mathrm{q} 22$ & 122 & $1.0(.02)$ & PD-ADHD \\
\hline $8 q 24$ & 150 & $1.6(.005)$ & PA-ADHD, PD-ADHD (0.8@ @ 144) \\
\hline $13 \mathrm{q} 32$ & 80 & $1.1(.02)$ & OC-ADHD, WR-ADHD (0.9@ 82), PA-ADHD (0.7@ 80), PD-ADHD (0.7@ 88) \\
\hline $14 \mathrm{q} 12$ & 12 & $1.9(.003)$ & ADHD, OC-ADHD (0.9@ 2) \\
\hline $14 \mathrm{q} 32$ & 142 & $2.5(.0008)$ & OC-ADHD, WR-ADHD (0.8@ 142), ADHD (0.6@ 144) \\
\hline $16 \mathrm{p} 13$ & 8 & $1.0(.02)$ & ADHD \\
\hline $20 \mathrm{q} 11$ & 56 & $2.2(.002)$ & OC-ADHD \\
\hline
\end{tabular}

$\mathrm{WR}=$ word recognition, $\mathrm{PA}=$ phonological awareness, $\mathrm{PD}=$ phonological decoding, $\mathrm{OC}=$ orthographic coding, $\mathrm{ADHD}=$ total ADHD symptoms. 
We have found evidence for a novel locus affecting several of the bivariate RD-ADHD phenotypes at chromosome 14q32 (Multipoint LOD = 2.5; Singlepoint LOD $=3.9$ ). This locus may harbor a potential pleiotropic gene that influences both RD and ADHD. The univariate ADHD phenotype was only marginally linked at this region, although ADHD and INAT were also linked to a more centromeric region. Interestingly, neither significant nor suggestive evidence for linkage at this locus has been reported in any of the $\mathrm{RD}$ and ADHD genome scans that have been conducted to date, although a peak (LOD $>1$ ) in this $14 q$ region was found for two ADHD phenotypes in one of the scans (Bakker et al., 2003). Perhaps the effect of this locus is more prominent in a comorbid sample like the one used for the bivariate analyses in the present study.

Evidence for bivariate linkage was also found for 13q32 (Multipoint LOD $=2.4$ for OC-HYP phenotype), a result supported by singlepoint analyses and multiple phenotypes. This region has also been implicated in previous univariate $\mathrm{RD}$ and ADHD scans (Table 1), providing further support for the hypothesis that this locus may be pleiotropic for RD and ADHD. Another potential pleiotropic locus is 20q11 (Multipoint $\mathrm{LOD}=2.2$; Singlepoint $\mathrm{LOD}=$ 2.3), which was linked to the OC-ADHD phenotype. A region close to this one (20q13) was linked to ADHD in a previous study (Table 1).

Three ADHD univariate linkage regions were located at $7 \mathrm{q} 21$ (LOD $=3.2$ for HYP), 9p24 (LOD $=2.6$ for INAT) and $16 \mathrm{p} 13$ (Singlepoint $\mathrm{LOD}=2.4$ for ADHD). The HYP region in chromosome 7 covers a large section of $7 \mathrm{p}$ and $7 \mathrm{q}$, overlapping the previously observed linkage for ADHD (Bakker et al., 2003). This region also contains one of the candidate genes that has previously been proposed for influencing ADHD (Dopa decarboxylase, involved in the dopaminergic pathway), making this an interesting replication. Nevertheless, there is some bivariate linkage to a region about 20 centimorgans away, so perhaps this locus is shared with RD. The 9p24 region seems the only specific ADHD effect found in the present study. We have also confirmed the $16 \mathrm{p} 13$ locus (Ogdie et al., 2003), which is linked to our univariate ADHD phenotypes, and it may also have pleiotropic effects. This linkage region has been suggested as a shared RD-ADHD locus (Loo et al., 2004), and it has also been implicated in autism (IMGSAC, 2001). More recently, a glutamate receptor gene which resides in this region has been associated with ADHD (Turic et al., 2004).

A majority of the loci suggested in this study with LOD scores $\geq 1$ have previously been reported to be linked to either RD or ADHD, or both: $2 \mathrm{p} 25,2 \mathrm{p} 11$ q14 (DYX3), 4q13, 5q31-33, 6p22 (DYX2), 7p15-21, 13q32-33, 16p13, 17q25, and 20q11-13 (see Table 1 for references). Some of these reported loci are small peaks on broad regions of linkage and should be interpreted cautiously. Nonetheless, all of these loci are potentially pleiotropic to RD and ADHD. Since the sample employed in this current study is an extension of the previous pleiotropic 6p study (Willcutt et al., 2002), the current results at this locus should be considered only as a re-analysis confirming the previous evidence.

Several of the most significant loci in this study were linked to a RD-ADHD bivariate phenotype, with OC being the RD phenotype. However, it would be premature to claim that these loci are specific to $\mathrm{OC}$, or to any component of RD or ADHD. The reason for the different effect sizes observed across variables in this study is probably due to sampling issues or chance.

Interestingly, no significant univariate ADHD or bivariate linkage was found for the known RD loci on chromosomes 1 (DYX8), 11 (DYX7), or 18 (DYX6), suggesting that these loci may have a unique effect on RD. Although we did not find ADHD linkage to the RD loci on chromosomes 3 (DYX5) and 15 (DYX1), other studies have (Bakker et al., 2003). We have also not replicated the $5 p$ linkage for ADHD, the only region shared by the two previous ADHD scans. However, the potential pleiotropy of these loci cannot be ruled out. Due to the small sample size of selected sibling pairs some possible bivariate loci might have been missed. Nonetheless, the bivariate regression method employed is a powerful test of linkage, especially suited for samples that have been selected for extreme deficits, like the one used in this study. The obtained linkage results are encouraging and suggest that methodological advances, such as the proposed bivariate linkage method, may help discern the genetics of complex disorders.

The immediate practical implications of our linkage results are limited. The current results add to the previous literature suggesting that comorbidity between RD and ADHD is due in part to common genetic influences. Therefore, when clinicians assess $\mathrm{RD}$ or ADHD, they should screen carefully for the other disorder. In the future, however, behavioral and molecular genetic studies are likely to improve methods for early identification of children at risk for $\mathrm{RD}, \mathrm{ADHD}$, or both disorders, and may even facilitate the development of interventions tailored to each individual's specific profile of risk and protective factors.

Other peaks identified in this scan are shared with other disorders. For example, the 2p25, 2p11-q14, $9 \mathrm{p} 24,16 \mathrm{p} 13$, and $17 \mathrm{q} 25$ peaks are shared with autism (IMGSAC, 2001), while the 13q locus has been implicated in both SLI and autism (Bartlett et al., 2001; CLSA, 2001). Although we do not have phenotypic data on these disorders to test for bivariate linkage, it is still interesting to note these potential common genetic effects. It is important to note again that because most of these linkage peaks are defined by small LOD scores, these conclusions are merely suggestive and require further confirmation in independent samples. Future studies might 
benefit from collecting multiple phenotypic information to potentiate the study of comorbidity.

Table 3 reports empirical pointwise significance levels for our main linkage peaks. Although we have analyzed multiple phenotypes, a Bonferroni correction would be too conservative since all these phenotypes are correlated. Thus, it is important to note that the reported significance levels have not been adjusted for multiple testing. Nonetheless, we ran simulations which allowed us to report empirical $p$-values, adjusting for any bias in significance levels potentially introduced by the data employed in the analysis (i.e., phenotype distribution, sample structure, etc.).

Some of our linkage results are greater for the bivariate analysis than for both of the corresponding univariate analyses. This could perhaps be due to the different sample sizes available in each task, but caution is advised in the interpretation of these results in particular.

The sample utilized in this study was recruited because at least one sibling in each pair exhibited evidence of learning difficulties in their school records. Because learning difficulties are significantly associated with ADHD, this method of ascertainment yielded a larger number of probands with ADHD than would be expected in an unselected sample. Although the use of a sample enriched for ADHD provided greater statistical power for the linkage analyses, this sampling procedure could yield different results than are obtained in samples directly selected for ADHD. The fact that many of the regions of linkage reported here overlap with those reported in previous linkage studies of RD and ADHD provides some support for the generalizability of our results. Nonetheless, the results of the univariate linkage analyses of ADHD should be considered exploratory, and should be interpreted with caution until they can be replicated in an independent sample selected directly for ADHD. In addition, ADHD symptoms were assessed by parent ratings of DSM-III ADHD symptoms. Future studies should test if these results replicate when ADHD is assessed by teacher ratings and when ADHD probands are defined by full DSM-IV diagnostic criteria.

Morley et al. (2004) recently reported that master regulators of gene expression are located at $14 \mathrm{q} 32$ and 20q13. Thus, the effects of the bivariate QTLs that we have localized to these two regions may be mediated by co-regulating the levels of expression of other genes.

\section{Conclusion}

In summary, the first bivariate genome-wide analysis of RD and ADHD revealed loci that are specific to RD, loci that are specific to ADHD, and several loci that may have pleiotropic effects on both $\mathrm{RD}$ and ADHD, suggesting that the comorbidity between RD and ADHD is due in part to common genetic influences. In addition, several linkage peaks revealed in our scan are shared with areas of peak linkage in other disorders. Such pleiotropic genes may be the rule, rather than the exception, in the etiology of complex characters.

\section{Acknowledgements}

This work was supported in part by Program Project and Center grants from the NICHD (HD-11681 and HD-27802) and by the Wellcome Trust. The contributions of the families and the staff members of the many Colorado school districts that participate in our research are gratefully acknowledged. We also wish to thank helpful comments from anonymous reviewers. A.P.M. and L.R.C. are Wellcome Trust Principal Research Fellows. S.E.F. is a Royal Society Research Fellow.

\section{Electronic-database information}

Human Gene Nomenclature Database, http:// www.gene.ucl.ac.uk/nomenclature/

\section{Correspondence to}

Javier Gayán, Wellcome Trust Centre for Human Genetics, University of Oxford, Roosevelt Drive, Oxford, OX3 7BN, UK; Tel: +44 1865287 718; Fax: +44 1865287 697; Email: gayan@well.ox.ac.uk

\section{References}

Abecasis, G.R., Cherny, S.S., Cookson, W.O.C., \& Cardon, L.R. (2002). Merlin - rapid analysis of dense genetic maps using sparse gene flow trees. Nature Genetics, 30, 97-101.

American Psychiatric Association. (1980). Diagnostic and statistical manual of mental disorders, 3rd edition. Washington, DC: American Psychiatric Association.

American Psychiatric Association. (1994). Diagnostic and statistical manual of mental disorders, 4th edition. Washington, DC: American Psychiatric Association.

Arcos-Burgos, M., Castellanos, F.X., Pineda, D., Lopera, F., Palacio, J.D., Palacio, L.G., Rapoport, J.L., Berg, K., Bailey-Wilson, J.E., \& Muenke, M. (2004). Attention-deficit/hyperactivity disorder in a population isolate: Linkage to loci at 4q13.2, 5q33.3, 11q22, and $17 \mathrm{p} 11$. American Journal of Human Genetics, 75, 998-1014.

Bakker, S.C., der Meulen, E.M., Buitelaar, J.K., Sandkuijl, L.A., Pauls, D.L., Monsuur, A.J., van't Slot, R., Minderaa, R.B., Gunning, W.B., Pearson, P.L., \& Sinke, R.J. (2003). A whole-genome scan in 164 Dutch sib pairs with attention-deficit/hyperactivity disorder: Suggestive evidence for linkage on chromosomes $7 \mathrm{p}$ and 15q. American Journal of Human Genetics, 72, 1251-1260. 
Bartlett, C.W., Flax, J.F., Logue, M.W., Vieland, V.J., Bassett, A.S., Tallal, P., \& Brzustowicz, L.M. (2001). A major susceptibility locus for specific language impairment is located on chromosome 13q21. American Journal of Human Genetics, 71, 45-55.

Bisgaard, M.L., Eiberg, H., Møller, N., Niebuhr, E., \& Morh, J. (1987). Dyslexia and chromosome 15 heteromorphism: Negative LOD score in a Danish material. Clinical Genetics, 32, 118-119.

Cardon, L.R., Smith, S.D., Fulker, D.W., Kimberling, W.J., Pennington, B.F., \& DeFries, J.C. (1994). Quantitative trait locus for reading disability on chromosome 6. Science, 266, 276-279.

Cardon, L.R., Smith, S.D., Fulker, D.W., Kimberling, W.J., Pennington, B.F., \& DeFries, J.C. (1995). Quantitative trait locus for reading disability: Correction. Science, 268, 1553.

CLSA. (2001). An autosomal genomic screen for autism. American Journal of Medical Genetics, 105, 609-615.

Cope, N.A., Hill, G., van den Bree, M., Harold, D., Moskvina, V., Green, E.K., Owen, M.J., Williams, J., \& O'Donovan, M.C. (2004). No support for association between dyslexia susceptibility 1 candidate 1 and developmental dyslexia. Molecular Psychiatry advance online publication.

Defienbacher, K.E., Kenyon, J.B., Hoover, D.M., Olson, R.K., Pennington, B.F., DeFries, J.C., \& Smith, S.D. (2004). Refinement of the 6p21.3 quantitative trait locus influencing dyslexia: Linkage and association analyses. Human Genetics, 115, 128-138.

DeFries, J.C., Filipek, P.A., Fulker, D.W., Olson, R.K., Pennington, B.F., Smith, S.D., \& Wise, B.W. (1997). Colorado Learning Disabilities Research Center. Learning Disabilities: A Multidisciplinary Journal, 8, 7-19.

DeFries, J.C., \& Fulker, D.W. (1985). Multiple regression analysis of twin data. Behavior Genetics, 15, 467-473.

Dunn, L.M., \& Markwardt, F.C. (1970). Examiner's manual: Peabody Individual Achievement Test. Circle Pines, MN: American Guidance Service.

Fagerheim, T., Raeymaekers, P., Tønnessen, F.E., Pedersen, M., Tranebjærg, L., \& Lubs, H.A. (1999). A new gene (DYX3) for dyslexia on chromosome 2. Journal of Medical Genetics, 36, 664-669.

Faraone, S.V., Doyle, A.E., Mick, E., \& Biederman, J. (2001). Meta-analysis of the association between the 7-repeat allele of the dopamine D4 receptor gene and attention deficit hyperactivity disorder. American Journal of Psychiatry, 158, 1052-1057.

Faraone, S.V., Perlis, R.H., Doyle, A.E., Smoller, J.W., Goralnick, J.J., Holmgren, M.A., \& Sklar, P. (in press). Molecular genetics of attention deficit hyperactivity disorder. Biological Psychiatry.

Field, L.L., \& Kaplan, B.J. (1998). Absence of linkage of phonological coding dyslexia to chromosome 6p23p21.3 in a large family data set. American Journal of Human Genetics, 63, 1448-1456.

Fisher, S.E., \& DeFries, J.C. (2002). Developmental dyslexia: Genetic dissection of a complex cognitive trait. Nature Reviews Neuroscience, 3, 767-780.

Fisher, S.E., Francks, C., Marlow, A.J., MacPhie, I.L., Newbury, D.F., Cardon, L.R., Ishikawa-Brush, Y., Richardson, A.J., Talcott, J.B., Gayán, J., Olson, R.K., Pennington, B.F., Smith, S.D., DeFries, J.C.,
Stein, J.F., \& Monaco, A.P. (2002a). Independent genome-wide scans identify a chromosome 18 quantitative-trait locus influencing dyslexia. Nature Genetics, 30, 86-91.

Fisher, S.E., Francks, C., McCracken, J.T., McGough, J.J., Marlow, A.J., MacPhie, I.L., Newbury, D.F., Crawford, L.R., Palmer, C.G.S., Woodward, J.A., Del'Homme, M., Cantwell, D.P., Nelson, S.F., Monaco, A.P., \& Smalley, S.L. (2002b). A genomewide scan for loci involved in attention-deficit/hyperactivity disorder. American Journal of Human Genetics, 70, 1183-1196.

Fisher, S.E., Marlow, A.J., Lamb, J., Maestrini, E., Williams, D.F., Richardson, A.J., Weeks, D.E., Stein, J.F., \& Monaco, A.P. (1999). A quantitative trait locus on chromosome $6 p$ influences different aspects of developmental dyslexia. American Journal of Human Genetics, 64, 146-156.

Francks, C., Paracchini, S., Smith, S.D., Richardson, A.J., Scerri, T., Cardon, L.R., Marlow, A.J., MacPhie, I.L., Walter, J., Pennington, B.F., Fisher, S.E., Olson, R.K., DeFries, J.C., Stein, J.F., \& Monaco, A.P. (2004). A 77-kilobase region of chromosome 6 p22.2 is associated with dyslexia in families from the United Kingdom and from the United States. American Journal of Human Genetics, 75, 1046-1058.

Froster, U., Schulte-Körne, G., Hebebrand, J., \& Remschmidt, H. (1993). Cosegregation of balanced translocation $(1 ; 2)$ with retarded speech development and dyslexia. The Lancet, 342, 178-179.

Fulker, D.W., Cardon, L.R., DeFries, J.C., Kimberling, W.J., Pennington, B.F., \& Smith, S.D. (1991). Multiple regression analysis of sib-pair data on reading to detect quantitative trait loci. Reading and Writing: An Interdisciplinary Journal, 3, 299313.

Gayán, J., \& Olson, R.K. (2001). Genetic and environmental influences on orthographic and phonological skills in children with reading disabilities. Developmental Neuropsychology, 20, 483-507.

Gayán, J., Olson, R.K., Cardon, L.R., Smith, S.D., Fulker, D.W., Kimberling, W.J., Pennington, B.F., \& DeFries, J.C. (1995). Quantitative trait locus for different measures of reading disability. Behavior Genetics, 25, 266.

Gayán, J., Smith, S.D., Cherny, S.S., Cardon, L.R., Fulker, D.W., Brower, A.M., Olson, R.K., Pennington, B.F., \& DeFries, J.C. (1999). Quantitative trait locus for specific language and reading deficits on chromosome 6p. American Journal of Human Genetics, 64, 157-164.

Grigorenko, E.L., Wood, F.B., Golovyan, L., Meyer, M., Romano, C., \& Pauls, D.L. (2003). Continuing the search for dyslexia genes on 6p. American Journal of Medical Genetics, Part B, 118B, 89-98.

Grigorenko, E.L., Wood, F.B., Meyer, M.S., Hart, L.A., Speed, W.C., Shuster, A., \& Pauls, D.L. (1997). Susceptibility loci for distinct components of developmental dyslexia on chromosomes 6 and 15. American Journal of Human Genetics, 60, 27-39.

Grigorenko, E.L., Wood, F.B., Meyer, M.S., \& Pauls, D.L. (2000). Chromosome 6p influences on different dyslexia-related cognitive processes: Further confirmation. American Journal of Human Genetics, 66, 715-723. 
Grigorenko, E.L., Wood, F.B., Meyer, M.S., Pauls, J.E.D., Hart, L.A., \& Pauls, D.L. (2001). Linkage studies suggest a possible locus for developmental dyslexia on chromosome 1p. American Journal of Medical Genetics, 105, 120-129.

Herjanic, B., \& Reich, W. (1982). Development of a structured psychiatric interview for children: Agreement between child and parent on individual symptoms. Journal of Abnormal Child Psychology, 10, 307324.

Hsiung, G.Y.R., Kaplan, B.J., Petryshen, T.L., Lu, S., \& Field, L.L. (2004). A dyslexia susceptibility locus (DYX7) linked to dopamine D4 receptor (DRD4) region on chromosome $11 \mathrm{p} 15.5$. American Journal of Medical Genetics, 125B, 112-119.

IMGSAC. (2001). A genomewide screen for autism: Strong evidence for linkage to chromosomes 2q, 7q, and 16p. American Journal of Human Genetics, 69, 570-581.

Kaminen, N., Hannula-Jouppi, K., Kestilä, M., Lahermo, P., Muller, K., Kaaranen, M., Myllyluoma, B., Voutilainen, A., Lyytinen, H., Nopola-Hemmi, J., \& Kere, J. (2003). A genome scan for developmental dyslexia confirms linkage to chromosome $2 \mathrm{p} 11$ and suggests a new locus on 7q32. Journal of Medical Genetics, 40, 340-345.

Kaplan, D.E., Gayán, J., Ahn, J., Won, T.W., Pauls, D., Olson, R.K., DeFries, J.C., Wood, F., Pennington, B.F., Page, G.P., Smith, S.D., \& Gruen, J.R. (2002). Evidence for linkage and association with reading disability on 6p21.3-22. American Journal of Human Genetics, 70, 1287-1298.

LaBuda, M.C., DeFries, J.C., \& Fulker, D.W. (1986). Multiple regression analysis of twin data obtained from selected samples. Genetic Epidemiology, 3, 425433.

Lessem, J.M., \& Cherny, S.S. (2001). DeFries-Fulker multiple regression analysis of sibship QTL data: A SAS r macro. Bioinformatics, 17, 371-372.

Loo, S.K., Fisher, S.E., Francks, C., Ogdie, M.N., MacPhie, I.L., Yang, M., McCracken, J.T., McGough, J.J., Nelson, S.F., Monaco, A.P., \& Smalley, S.L. (2004). Genome-wide scan of reading ability in affected sibling pairs with attention-deficit/hyperactivity disorder: Unique and shared genetic effects. Molecular Psychiatry, 9, 485-493.

Lyon, G.R. (1995). Toward a definition of dyslexia. Annals of Dyslexia, 45, 3-27.

Maher, B.S., Marazita, M.L., Ferrell, R.E., \& Vanyukov, M.M. (2002). Dopamine system genes and attention deficit hyperactivity disorder: A meta-analysis. Psychiatric Genetics, 12, 207-215.

Marino, C., Giorda, R., Vanzin, L., Nobile, M., Lorusso, M.L., Baschirotto, C., Riva, L., Molteni, M., \& Battaglia, M. (2004). A locus on 15q15-15qter influences dyslexia: Further support from a transmission/disequilibrium study in an Italian speaking population. Journal of Medical Genetics, 41, 42-46.

Marlow, A.J., Fisher, S.E., Francks, C., MacPhie, I.L., Cherny, S.S., Richardson, A.J., Talcott, J.B., Stein, J.F., Monaco, A.P., \& Cardon, L.R. (2003). Use of multivariate linkage analysis for dissection of a complex cognitive trait. American Journal of Human Genetics, 72, 561-570.
Morley, C.M., Weber, T.M., Devlin, J.L., Ewens, K.G., Spielman, R.S., \& Cheung, V.G. (2004). Genetic analysis of genome-wide variations in human gene expression. Nature, 430, 743-747.

Morris, D.W., Robison, L., Turic, D., Duke, M., Webb, V., Milham, C., Hopkin, E., Pound, K., Fernando, S., Easton, M., Hamshere, M., Williams, N., McGufin, P., Stevenson, J., Krawczak, M., Owen, M.J., O’Donovan, M.C., \& Williams, J. (2000). Family-based association mapping provides evidence for a gene for reading disability on chromosome 15q. Human Molecular Genetics, 9, 843-848.

Nichols, R.C., \& Bilbro, W.C. (1966). The diagnosis of twin zygosity. Acta Genetica et Statistica Medica, 16, 265-275.

Nopola-Hemmi, J., Myllyluoma, B., Haltia, T., Taipale, M., Ollikainen, V., Ahonen, T., Voutilainen, A., Kere, J., \& Widen, E. (2001). A dominant gene for developmental dyslexia on chromosome 3. Journal of Medical Genetics, 38, 658-664.

Nopola-Hemmi, J., Taipale, M., Haltia, T., Lehesjoki, A.E., Voutilainen, A., \& Kere, J. (2000). Two translocations of chromosome $15 \mathrm{q}$ associated with dyslexia. Journal of Medical Genetics, 37, 771-775.

Ogdie, M.N., MacPhie, I.L., Minassian, S.L., Yang, M., Fisher, S.E., Francks, C., Cantor, R.M., McCracken, J.T., McGough, J.J., Nelson, S.F., Monaco, A.P., \& Smalley, S.L. (2003). A genomewide scan for attention-deficit/hyperactivity disorder in an extended sample: Suggestive linkage on $17 \mathrm{p} 11$. American Journal of Human Genetics, 72, 1268-1279.

Olson, R.K., Forsberg, H., \& Wise, B. (1994). Genes, environment, and the development of orthographic skills. In V.W. Berninger (Ed.), The varieties of orthographic knowledge I: Theoretical and developmental issues (pp. 27-71). Dordrecht, The Netherlands: Kluwer Academic Publishers.

Olson, R.K., Rack, J.P., Conners, F.A., DeFries, J.C., \& Fulker, D.W. (1991). Genetic etiology of individual differences in reading disability. In L.V. Feagans, E.J. Short, \& L.J. Meltzer (Eds.), Subtypes of learning disabilities (pp. 113-135). Hillsdale, NJ: Lawrence Erlbaum.

Olson, R.K., Wise, B., Conners, F., Rack, J., \& Fulker, D. (1989). Specific deficits in component reading and language skills: Genetic and environmental influences. Journal of Learning Disabilities, 22, 339348.

Petryshen, T.L., Kaplan, B.J., Hughes, M.L., Tzenova, J., \& Field, L.L. (2002). Supportive evidence for the DYX3 dyslexia susceptibility gene in Canadian families. Journal of Medical Genetics, 39, 125-126.

Petryshen, T.L., Kaplan, B.J., Liu, M.F., \& Field, L.L. (2000). Absence of significant linkage between phonological coding dyslexia and chromosome 6p23-p21.3, as determined by use of quantitativetrait methods: Confirmation of qualitative analyses. American Journal of Human Genetics, 66, 708-714.

Petryshen, T.L., Kaplan, B.J., Liu, M.F., Schmill, de French, N., Tobias, R., Hughes, M.L., \& Field, L.L. (2001). Evidence for a susceptibility locus on chromosome $6 \mathrm{q}$ influencing phonological coding dyslexia. Journal of Medical Genetics, 105, 507-517.

Rabin, M., Wen, X.L., Hepburn, M., Lubs, H.A., Feldman, E., \& Duara, R. (1993). Suggestive linkage of 
developmental dyslexia to chromosome 1p34-p36. The Lancet, 342, 178.

Scerri, T.S., Fisher, S.E., Francks, C., MacPhie, I.L., Paracchini, S., Richardson, A.J., Stein, J.F., \& Monaco, A.P. (2004). Putative functional alleles of DYX1C1 are not associated with dyslexia susceptibility in a large sample of sibling pairs from the UK. Journal of Medical Genetics, 41, 853-857.

Schulte-Körne, G., Grimm, T., Nöthen, M.M., MüllerMyhsok, B., Cichon, S., Vogt, I.R., Propping, P., \& Remschmidt, H. (1998). Evidence for linkage of spelling disability to chromosome 15. American Journal of Human Genetics, 63, 279-282.

Smith, S.D., Kimberling, W.J., \& Pennington, B.F. (1991). Screening for multiple genes influencing dyslexia. Reading and Writing: An Interdisciplinary Journal, 3, 285-298.

Smith, S.D., Kimberling, W.J., Pennington, B.F., \& Lubs, H.A. (1983). Specific reading disability: Identification of an inherited form through linkage analysis. Science, 219, 1345-1347.

Stein, C.M., Schick, J.H., Taylor, G., Shriberg, L.D., Millard, C., Kundtz-Kluge, A., Russo, K., Minich, N., Hansen, A., Freebairn, L.A., Elston, R.C., Lewis, B.A., \& Iyengar, S.K. (2004). Pleiotropic effects of a chromosome 3 locus on speech-sound disorder and reading. American Journal of Human Genetics, 74, 283-297.

Taipale, M., Kaminen, N., Nopola-Hemmi, J., Haltia, T., Myllyluoma, B., Lyytinen, H., Muller, K., Kaaranen, M., Lindsberg, P.J., Hannula-Jouppi, K., \& Kere, J. (2003). A candidate gene for developmental dyslexia encodes a nuclear tetratricopeptide repeat domain protein dynamically regulated in brain. Proceedings of the National Academy of Science U.S.A., 100, 11553-11558.

Turic, D., Langley, K., Mills, S., Stephens, M., Lawson, D., Govan, C., Williams, N., Van den Bree, M.,
Craddock, N., Kent, L., Owen, M., O’Donovan, M., \& Thapar, A. (2004). Follow-up of genetic linkage findings on chromosome 16p13: Evidence of association of N-methyl-D aspartate glutamate receptor 2A gene polymorphism with ADHD. Molecular Psychiatry, 9, 169-173.

Tzenova, J., Kaplan, B.J., Petryshen, T.L., \& Field, L.L. (2004). Confirmation of a dyslexia susceptibility locus on chromosome 1p34-p36 in a set of 100 Canadian families. American Journal of Medical Genetics, 127B, 117-124.

Wigg, K.G., Couto, J.M., Feng, Y., Anderson, B., CateCarter, T.D., Macciardi, F., Tannock, R., Lovett, M.W., Humphries, T.W., \& Barr, C.L. (2004). Support for EKN1 as the susceptibility locus for dyslexia on 15q21. Molecular Psychiatry, 9, 1111-1121.

Willcutt, E.G., \& Pennington, B.F. (2000). Comorbidity of reading disability and attention deficit/hyperactivity disorder: Differences by gender and subtype. Journal of Learning Disabilities, 33, 179-191.

Willcutt, E.G., Pennington, B.F., Olson, R.K., Chhabildas, N., \& Hulslander, J. (2005). Neuropsychological analyses of comorbidity between RD and ADHD: In search of the common deficit. Developmental Neuropsychology, 27, 35-78.

Willcutt, E.G., Pennington, B.F., Olson, R.K., \& DeFries, J.C. (submitted). Understanding comorbidity: A twin study of reading disability and attention-deficit/ hyperactivity disorder.

Willcutt, E.G., Pennington, B.F., Smith, S.D., Cardon, L.R., Gayán, J., Knopik, V.S., Olson, R.K., \& DeFries, J.C. (2002). Quantitative trait locus for reading disability on chromosome $6 \mathrm{p}$ is pleiotropic for attention-deficit/hyperactivity disorder. American Journal of Medical Genetics (Neuropsychiatric Genetics), 114, 260-268.

Manuscript accepted 6 December 2004 